\title{
TRANSGENDER ATHLETES: THE BALANCE BETWEEN PERSONAL DATA PROTECTION AND THE FAIR COMPETITION PRINCIPLE
}

\author{
Anna DI GIANDOMENICO ${ }^{*}$ \\ ${ }^{1}$ University of Teramo, Faculty of Political Science, Teramo, Italy \\ *Corresponding author: adigiandomenico@unite.it
}

DOI: https://doi.org/10.51267/icpesk2020bp04

\begin{abstract}
The right of transgender athletes to participate in sports competitions no longer seems to be in question, even if this is a right only recently established. DSD (Disorders of Sexual Development), having a genetic nature, are more widespread than perceived (about one person affected every 2500 births). To these, we have to add all individuals whose sexual identification arises for psychological reasons. Given that, it is obvious how the question is much more important (in numerical terms) of what is currently emerging. We want to focus on the hard balance between personal data protection and the fair competition principle, after the entry into force of the EU General Data Protection Regulation (GDPR), on 25 May 2018. According to GDPR rules, it is prohibited to process data concerning health or sex life. Thus, data regarding sexual identity and/or any changes in gender-related sex fall under special protection. In terms of sports law, IOC Consensus Meeting on Sex Reassignment and Hyperandrogenism (November 2015) reformed previous Stockholm Consensus on Sex Reassignment in Sports (1973). According to it, the completion of surgical anatomical changes is no longer a sine qua non condition, being sufficient the declaration of the gender by athletes. Recalling how athletes have to compete according to the fair competition principle, we wonder if European regulation collides with the respect of this principle. How can we balance them? How can we solve this conflict under the GDPR rules, coordinated with the norms of legal sports systems?
\end{abstract}

Keywords: transgender athletes, fair competition principle, GDPR.

\section{Introduction}

The right of transgender athletes to participate in sports competitions no longer seems to be in question, even if this is a right only recently established. A right whose recognition shared some traits of the broader struggle for recognition of the rights of the LGBT (Lesbian, Gay, Bisexual, and Transgender) community. This struggle concerned several aspects, such as the right to the access of bathrooms and locker rooms according to perceived or re-assigned sex, or the most general right to participate in sports competitions with athletes of sex other than the one assigned at birth.

Disorders of Sex Differentiation (DSD), having a genetic nature, are more widespread than perceived (about one person affected every 2500 births). To these, we have to add all individuals whose sexual identification arises for psychological reasons. Given that, it is obvious how the question is much more important (in numerical terms) of what is currently emerging.

We want to focus on the hard balance between personal data protection and the fair competition principle, after the entry into force of the EU General Data Protection Regulation (EU Regulation 2016/679), henceforth GDPR, whose rules are effective since 25 May 2018. 


\section{Transgender: A general overview}

Before entering into the merit, it seems important to outline the defining boundaries, which will be object of our consideration.

First, we will use gender and sex as synonymous, but we are aware that sexual belonging is the result of several factors (physiological, genetic, psychological, cultural), which contribute to the process of formation of individuality. It is a process in which both gender and role identity, as well as the biological/genetic belonging to a sex, perform a function (Lips, 2020).

On this premise, we mean as transgender a person whose gender identity does not correspond to the gender he or she got assigned at birth, i.e. there is a discrepancy between biological sex and gender (Castagnoli, 2010).

According to this definition, many kinds of persons can be considered transgender: in particular, we can consider as transgender all persons affected by DSD (also defined as GD Gender Dysphoria, or GID - Gender Identity Disorder) having a genetic nature, as well as all persons whose sexual misidentification depends on psychological reasons. The common characteristic is that the "official" gender does not coincide with the true (genetic and/or perceived) gender.

As regards the first type of persons, it seems interesting to underline how DSD have a very high frequency: statistics indicate an incidence of 17 children affected by DSD every 1000 new-borns (Hester, 2004; Blackless et al., 2000). To give an idea of the frequency, it is sufficient to point out how there is a cystic fibrosis born for every 2500 new-borns, a person with Down syndrome for every 800/1000 new-borns, as well as we can detect a person affected by albinism every 17000 new-borns. According to Fausto-Sterling (2000) and Hester (2004), it appears equally important how not all people affected by DSD need surgery (only one person per 2000 new-borns). This implies that we are in the presence of affected people who are much more widespread and, at the same time, much more submerged than we imagine.

As told above, we have to add to these all other individuals having a misidentification with their official gender, which grounds on psychological reasons.

All these end up constituting a large group of people who may be interested in the question. A group characterised by an extreme and essential complexity (Hughes, 2008), which does not seem opportune to investigate here, being obviously out of the scope of this essay.

Given the awareness of the irrepressible complexity of the question, we go beyond without considering further distinctions, just assuming the definition of transgender person outlined above.

\section{Topic Addressed}

\section{Transgender athletes}

Assumed the breadth of potentially interested people, we can conclude that the question may be equally common in sport.

Retracing the steps of its emersion, we detect how transgender athletes' rights can concern at least two orders of questions: one having a general nature and the other being more specific. 
A first order of questions has a general nature, consisting in the call for a recognition of their condition, without discrimination due to their gender identity and/or expression. These claims shared some traits of the broader struggle for recognition of the rights of the LGBT community and concerned several aspects, such as the right to the access of bathrooms and locker rooms according to perceived or re-assigned sex.

A struggle for recognition that currently has uncertain outcomes in jurisprudence, despite very careful inclusion policies (van den Brink \& Dunne, 2018).

It seems important to point out how in Europe we detect a strong ban as regards any discrimination grounded on sexual orientation. Several EU Directives go in this sense, like the Council Directive 2000/78/EC and the Directive 2002/73/EC. To these, we have to add the Directive 2006/54/EC of the European Parliament and of the Council of 5 July 2006 on the implementation of the principle of equal opportunities and equal treatment of men and women in matters of employment and occupation.

This legal framework grounds on the art. 21, para 1, of the Charter of Fundamental Rights of European Union (hereafter CFREU), which expressly establishes: "any discrimination based on any ground such as sex, race, colour, ethnic or social origin, genetic feature, language, religion or belief, political or any other opinion, membership of a national minority, property, birth, disability, age or sexual orientation shall be prohibited". Remember how this regulatory provision is binding all over EU Member states, being part of the Treaty on the Functioning of the European Union (TFEU).

Despite such advanced and common legislation at the European level, the panorama of the condition of the transgender is truly different (Trans Rights Europe Map \& Index 2018). In fact, there are some states that adopt policies aimed at promoting and protecting human rights enjoyed by transgender, besides the setting of such a legal framework (among them, Denmark, France, Ireland, Netherlands, Portugal, Spain, Portugal, Sweden, and UK). But there are also some states whose actions are limited to the mere adoption of legislative measures without putting in place concrete policies aimed at countering their discrimination (among them, Bulgaria, Cyprus, Greece, Latvia, Lithuania, Poland, Romania, and Slovakia).

As regards Italy, there is without doubts an advanced legislation against discrimination, but there is not a concrete policy aimed at enforcing all that stated by law. The art. 1 of Law 14, no. 164 of April 1982, rules the sex reassignment, establishing the procedure for rectification of sex assignment, consisting in two different phases. The first one consists in ascertaining the right of the person to obtain the attribution of a different sex, with consequent authorisation to undergo the surgical treatment necessary for the purpose. This initial step starts with recourse to the Court and ends with a Court sentence. The second phase ends with a judgment too: it consists in ascertainment of the modification authorised by the Court (i.e. the demolition and reconstructive intervention of sex) and orders the attribution of the different sex and consequent correction of personal data to the competent official of civil status.

It seems important to underline how a recent judgment of Italian Constitutional Court established that "the surgical treatment is a possible tool, as an aid in order to guarantee [...] the achievement of a full mental and physical well-being of the person" (Constitutional Court, judgment 21 October 2015, no. 221, para 4.1 of juridical arguments). Nevertheless, the procedure as a whole implies waiting at least 5-6 years. 
This legal framework does not seem consistent with other concrete aspects of life: just think of how the debate on accessibility to toilets and changing rooms consistent with gender identity is still open and unsolved: as far as we are aware, there is no gender-neutral bathrooms.

Besides this general question, there is another more specific order of questions concerning the participation of transgender athletes in sports competitions, better the regulation of their participation, considering that participation of transgender athletes in sports competitions does not seem to be any longer questioned, even if this is a right only recently established.

At a first glance, it seems that the sports legal system took positions, certainly more advanced than those of some national legal systems. In fact, in 2004, IOC adopted the so-called Stockholm Consensus (drafted in 2003), by which it regulated the participation of athletes who had undergone sex reassignment.

This was the first official document expressly ruling the participation of transsexual athletes in sports competitions, but the sex verification is a practice dating back a long time ago (Ferguson Smith \& Ferris, 1991). Just remember how, until the early 60s, it consisted in physical examination, giving rise to the so-called "naked parades": a truly humiliating practice for sportswomen, often accompanied by a gynaecological examination (Ferguson Smith \& Ferris, 1991; Heggie, 2017). The detection of the Barr body substituted this practice in the late 60s: so, we detect the use of the buccal smear for the first time during the Mexico City Olympic Games. However, this test was not reliable because it gives controversial results if applied to people affected by some DSD (i.e. women affected by Turner's syndrome, as well as those affected by androgen insensibility syndrome). There were, in fact, unjust exclusions of some women from sports competitions following those exams (Simpson et al., 1993; Sullivan, 2011).

As regards the Stockholm Consensus, it is interesting how it prescribed some conditions in order to admit to sports competitions. More specifically, these conditions were: "surgical anatomical changes have been completed, including external genitalia changes and gonadectomy; legal recognition of their assigned sex has been conferred by the appropriate official authorities; hormonal therapy appropriate for the assigned sex has been administered in a verifiable manner and for a sufficient length of time to minimise gender-related advantages in sport competitions". Moreover, the Committee observed: "eligibility should begin no sooner than two years after gonadectomy".

Such a regulation gives rise to some criticisms because of its restrictiveness. Firstly, there is no medical evidence of the need to undergo a surgical removal of testes in addition to administration of hormone therapy (Carroll, 2017). Besides this just mentioned, another two issues arise: the first regards the requirement of a completed surgical anatomical change, while the second one regards the need to wait at least two years before being eligible. The first one was a requirement that could raise an obstacle to the participation of athletes, who, for economic reasons, cannot access surgery for the reassignment of sex, or who cannot have a legal recognition of the change, because the legislation of their countries does not allow it (Sykes, 2006). The second one was a further obstacle: it is a too much disadvantageous requirement, considering the long time needed for the ending of the reassignment processes as a whole. Too much time if compared with the brevity ordinarily characterising a sports career.

During a meeting on sex reassignment and hyperandrogenism held in Lausanne $(\mathrm{CH})$, in November 2015, IOC revised previous Stockholm Consensus, partially amending some critical issues, just highlighted. The participants took note of a "growing recognition of the importance 
of autonomy of gender identity in society" (IOC, 2015, pt. A), as well as of the need "to ensure insofar as possible that the trans-athletes are not excluded from the opportunity to participate in sporting competition". In light of these considerations, the new Guidelines abolish the mandatory completion of surgical changes, giving legal relevance and prevalence to the declaration made by the athlete (IOC, 2015, pt. 2.1). The detection of a testosterone level in serum below $10 \mathrm{nmol} / \mathrm{L}$ for at least 12 months prior to their first competition (IOC, 2015, pt. 2.2) and throughout all competitive period (IOC, 2015, pt. 2.3) are a sufficient guarantee in order to preserve fairness in competition.

\section{EU General Data Protection Regulation}

Coming into the examination of the EU GDPR, without claim to be exhaustive, here it is sufficient to highlight some of its distinctive features characterising the new data protection regulation after its entry into force all over EU states.

It seems important to underline how this is not the first regulation on data protection by the European Union. Before its enactment, a set of rules governed the matter: a set of rules constituted by the Directive 95/46/EC and some further norms (like the Directive on Privacy and Electronic Communications, 2002/58/EC). A complex legal framework that became complete considering some international agreements aimed at guaranteeing the protection of personal data as regards their transferring to third parties (i.e. Commission Decision 2000/520/EC).

The entry into force of the Lisbon Treaty highlighted the obsolescence of this legal framework, because of its recognition of the fundamental right to protection of personal data, according to what was stated by art. 16 TFEU and art. 8 of the Charter of Fundamental Rights.

The EU remedied this obsolescence by adopting the aforementioned GDPR, which seems to provide citizens with a very high level of protection.

A very high standard of protection ensured, first, by the type of legal instrument chosen: not more a Directive but a Regulation, which is a binding legislative act directly applicable in its entirety across the EU, without need of additional domestic implementation (art. 288 TFEU). Following this characteristic, a regulation becomes part of the state legal system, having effect on it, overriding any contrary national laws. This feature ensures more than the harmonisation of law on the matter: the regulation gives a uniform legislation, providing the same norms all over EU member states.

Going beyond these general remarks and entering into the merit of what disposed, firstly it seems important to underline how the adoption of GDPR confirmed the distinction made between the right to privacy and the right to dispose of personal data. This is a significant change of perspective based on the distinction already done by the CFREU, which disciplines the first one by art. 7, and the second by the abovementioned art. 8; a difference depicting the right to privacy as a negative liberty (Warren-Brandeis, 1890; Vested-Hansen, 2014; Choudhry, 2014) and the right to data protection as a right of the subject to control all information referred to him/her (Kranenborg, 2014; Lynksey, 2014; Finocchiaro, 2017, § 2).

Secondly, GDPR clearly specifies the principles according to which it is possible to process personal data: more specifically, it is possible to process personal data according to the principles of lawfulness, fairness, and transparency (art. 5.1a). Not only, data processing must 
also respect the principle of integrity and confidentiality (art. 5.1f), as well as it must comply with the principle of purpose limitation (art. 5.1b). Their collection must comply with the principle of data minimisation (art. 5.1c) and the principle of accuracy (art. 5.1d). Further, the principle of storage limitation rules the regime of keeping and storage of collected data (art. 5.1e), while a principle of accountability governs the activity of data controller (art. 5.2).

As regards what falls within the scope of our interest, GDPR expressly establishes a right to be forgotten (art. 17) and introduces an ad hoc article, regulating the consent of minors (art. 8). These two articles seem to strengthen the right to dispose of personal data: someone has defined these norms as a triumph of the so-called informational self-determination (Thiene, 2014, §2).

\section{Transgender athletes: Legal issues}

The above outlined regulations regarding transgender athletes highlight several legal issues at a general level, at a sports legal system level, as well as regards all that concerns the implementation of GDPR rules.

At a general level, as already observed, the fight against transgender people's discrimination needs that active policies accompany legislative regulations, if we want that these norms have true effectiveness. In this regard, we already underlined how, notwithstanding a European strong legal framework aimed at countering discrimination, national laws do not always follow European directives. In a word, there is still a long way to go in this direction.

At the level of sports legal systems, we have seen how IOC ruled the matter more specifically since 2004, even if it put in place checks in order to ascertain the sex of participants in sports competitions since the 1950s.

As noted above, IOC revised this specific regulation in 2015 because of some issues highlighted under the implementation of such regulation, as well because of the acknowledgment of cultural change, which made obsolete the previous discipline.

We wonder if the changes outlined above are sufficient. Preliminarily, it seems important to underline how this regulation grounds on the assumption that males have a physical advantage over all females: therefore, this regulation is part of the broader discourse related to fair play, or rather to the need to ensure a level playing field.

As already pointed out, IOC establishes a threshold of the testosterone level below 10 $\mathrm{nmol} / \mathrm{L}$, assuming the lower level of male's "normal" values as a reference parameter. The rationale of such a rule grounds on the assumption that male superiority in athletic performance essentially depends on the level of testosterone, which is higher than that ordinarily found in women (Gooren, 2008; Tucker \& Collins, 2009). However, even medical data go in this sense, the same data tell us that testosterone is not the only factor in giving a competitive advantage. Without doubts, it increases muscle size, strength, and endurance (Bhasin et al. 1996; Ronnestad et al., 2011; Storer et al., 2003), but there is no evidence that athletes with "higher endogenous testosterone perform better than athletes with lower levels" (Karzakis et al., 2012, p. 8). In fact, the difference in lean body mass between elite women athletes and elite male athletes is sufficient to justify the detected differences in performance, without the need to ascribe it to different testosterone levels (Healy et al., 2014). Not only, a research highlights that there is a significant overlap of results between sexes: in fact, the research detected a considerable number of male athletes with a low testosterone level, as well as several female 
athletes with a testosterone level higher than that one established by IAAF and IOC (Healy et al., 2014). Following these outcomes, it is obvious to conclude that the decision of the "IOC and IAAF to limit participation in elite events to women with a 'normal' serum testosterone is unsustainable" (Healy, 2014, p. 303).

Moreover, in establishing maximum levels of testosterone, this regulation seems to harm transgender athletes, because at least two orders of reasons.

The first one concerns a health profile: the need to lower testosterone can give rise to some adverse unwanted side effects (Archer \& Chang, 2004; Karkazis et al., 2012; Jordan-Young et al., 2014), without considering long-term effects, at the present not sufficiently known because of the lack of studies on the matter.

The second one regards a sports profile: forcing these athletes to keep low their testosterone levels paradoxically gives rise to a disadvantage for them, because the mandatory therapy needed to low testosterone level can determine the lengthening of recovery times from exertion, besides the abovementioned side effects.

Finally, focusing on the application of GDPR to trans-athletes participating in sport competitions, further issues emerge.

As told above, the regulation disposes a regime aimed at protecting personal data in a rigorous manner, outlining a right to control all information referring to an individual. In this way, a person can choose what and how much of himself/herself he/she wants to share or make public; not only that, they can decide to withdraw his/her consent, with a binding effect on the data owners, without the need to state his/her withdrawal's reasons.

Furthermore, it seems important to recall how GDPR distinguishes between personal data and sensitive data. These latter include data revealing racial or ethnic origin, political opinions, religious or philosophical beliefs, or trade union membership, as well as genetic data, biometric data, data concerning health or data concerning a natural person's sex life or sexual orientation (art. 9.1). GDPR establishes for such data a special protection regime, more rigorous than the strict one reserved for personal data. It appears evident how data related to the condition of trans-athletes falls within the field of competence of such stricter regime.

On the other hand, within the sports legal system, when these data conflict with the standards of admission to sports competitions, they inevitably must become public without any possibility of control by the subjects involved.

This is possible thanks to the conventional nature of sports legal system: athletes choose to become part of this specific legal system and, consequently accept its rules, even those that significantly limit their freedom (Foster, 2003).

We wonder how the conflict between EU GDPR and sports legal system can be solved. This is not a question easy to solve, considering the different status of sports legal system within each state.

If the sport falls totally or partially in the areas of competence of the state, its legal system has the distinctive feature of a subordinate legal order (at least sectorial) subjected however to the state regulatory constraints. In this case, the regulatory framework dictated by EU GDPR will prevail. However, the sports legal system is part of an international system: national federations are territorial articulations of an international federation and have to comply with its peculiar legal criteria if they do not want to incur in an expulsion order. If so, we wonder how such a loss of sovereignty at national level can be reconciled with the juridical principles 
in force within the international federation.

The question becomes more complex if there is a mutual indifference between state and the national sports legal system: how do reconcile this clash between these two legal systems? Which one prevails? Considering the strong power of disposal acknowledged to individual by the GDPR rules, we wonder what kind of recognition could receive such a power within the sports legal system. Better, what hope can an athlete have to exclude the disclosure regime for his/her data?

Further issues emerge considering the special condition of underage trans-athletes. As already pointed out, GDPR recognizes their capacity to give a consent in relation to the offer of information society services, if they are at least sixteen years old. This provision may give rise to some issues. In particular, how can be solved the clash among this provision and those in force in states where there is no room for an emancipation of minors, except some limited matters? Just remember how in Italy minors can emancipate themselves only in few cases, essentially concerning matters relating to marriage and the recognition of children (art. 390, Italian Civil Code), as well as the engagement in commercial activities (art. 397), while there is no room for consent as regards health decisions. Thus, we wonder what kind of relevance such a consent could have in these states where it is no room for emancipation of minors, except few and selected cases. Who will be entitled to act in the courts in case of legal disputes?

Not only, it is interesting to note how the special GDPR acknowledgment of the capacity of minors seems to comply with the status of minors within the sports legal system, which does not recognize them a special status, due to their condition. In this regard, it seems important to remember how the regime of responsibility of minors for doping violations is the same established for an adult: there is no mention of their status characterised by an essential legal incapacity, as well as there is no differentiation as regards sanctions (Di Giandomenico, 2016).

Notwithstanding this compliance, there emerges a further issue related to the disclosure of his/her transgender condition under the rules provided by the sports legal system. We wonder how we can reconcile the right not to divulge news concerning the sphere of gender identity with the public character that this condition has in the sports legal system. Moreover, considering that, as regards affiliation and association to a sport federation, an adult exercising the guardianship gives the consent pro minors, we wonder if this consent also extends to the processing of data relating to gender identity. If so, which extent can the exercise of the right to be forgotten have? Better, can a sixteen-years-old athlete exercise such a right? What kind of legal relevance can have such an exercise?

\section{Conclusion}

Concluding, we have seen how the condition of trans-athletes is truly complex, this condition being a big umbrella that shelters people with genetic disorders, as well as individuals suffering because of a sexual misidentification, depending on psychological reasons.

Their claims for participation in sports competitions consistent with their perceived gender is not more questioned but gives rise to several issues.

The first one regards the ascertainment of the lack of undue advantage (for MTF transathletes). Several scholars deepened and still deepen the matter, without achieving a common point of view due to the objective difficulty in reconciling the right to be recognized in one's 
gender identity and to ensure respect for the equally fundamental principle of fairness in sports competitions (Ingram \& Thomas, 2019; Müller, 2016; Sudai, 2017; Sullivan, 2011).

The second one arises when we consider the consequences of the entry into force of EU GDPR, which introduced a strict regime of sensitive data protection. Following its rules, any information related to genetic data, data concerning health or data concerning a natural person's sex life or sexual orientation falls within this field. It seems evident how there is a clash between the need to protect undue spread of such information with the public regime to which this information must be subjected in order to ensure the level playing field.

There is an even stronger contrast if the people concerned are underage athletes. As above explained, despite an apparent compliance of GDPR rules with the minors' condition under sports legal systems, we wonder if it is admissible to extent the consent given by these underage athletes to information related to their gender identity.

However, focusing on IOC rules on the matter, there emerges its leading role for the acknowledgement of the rights of transgender people. Despite this undoubtable precious contribution to their cause, IOC rules highlight some issues. The true critical point is that new IOC Guidelines ground on the premise that the measure of testosterone level is sufficient to define an athlete as male or female. Thus, these Guidelines highlight an essential contradiction. They affirm, on the one hand, the need to ensure to give trans-athletes the opportunity to participate in sports competitions and, on the other hand, keep the binary sex classification system intact (Müller, 2016; Sudai, 2017), completely ignoring that human biology is truly complex, being too simplistic to reduce it to a single representative factor.

More, assumed the need of ensuring of level playing field and, at the same time, of giving trans-athletes the opportunity of competing, we wonder if it is so inconceivable to provide an approach similar to that one adopted by Paralympic sports, consisting in a classification listed according to the types of impairment (Sudai, 2017). The introduction of a new way of classification allows to identify for each athlete (trans- or not) a class of belonging, depending on known biological elements that provide a competitive edge (i.e. LBM, height, vision, muscle strength, oxygen carrying red blood cells, lung size, and so on) and compete with athletes of the same class. This classification seems to give a more appropriate response to the claims for participation of trans-athletes in sports competitions without undergoing humiliation, if not harmful practices and/or therapies, and, at the same time, to the issue related to an alleged edge of trans- MTF athletes. Is this a utopian or concretely viable proposal?

\section{References}

Archer, J. S., \& Chang, R. J. (2004). Hirsutism and acne in polycystic ovary syndrome. Best Practice \& Research Clinical Obstetrics and Gynaecology, 18(5), 737-754. https://doi.org/10.1080/gye.16.4.275.284

Article 390, Italian Civil Code. https://www.brocardi.it/codice-civile/libro-primo/titolox/capo-ii/art390.html

Article 397, Italian Civil Code. https://www.brocardi.it/codice-civile/libro-primo/titolox/capo-ii/art397.html

Bhasin, S., Storer, T. W., Berman, N., Callegari, C., Clevenger, B., Phillips, J., Bunnell, T. J., Tricker, R., Shirazi, A., \& Casaburi, A. (1996). The effects of supraphysiologic doses of testosterone on muscle size and strength in normal men. The New England Journal of 
Medicine, 335(1), 1-7. https://doi.org/10.1056/nejm199607043350101

Blackless, M., Charuvastra, A., Derryck, A., Fausto-Sterling, A., Lauzanne, K., \& Lee, E. (2000). How sexually dimorphic are we? Review and synthesis. American Journal of Human Biology, 12(2), 151-166.

https://doi.org/10.1002/(SICI)1520-6300(200003/04)12:2<3C151::AID-

AJHB1>3E3.0.CO;2-F

Carroll, H. J. (2017). Including transgender students in United States' school-based athletics. In E. Anderson \& A. Travers (Eds.), Transgender athletes in competitive sport (pp. 143155). London: Routledge.

Castagnoli, C. (2010). Transgender persons' right in the EU member states. Brussels: European Parliament.

https://www.europarl.europa.eu/RegData/etudes/note/join/2010/425621/IPOLLIBE_NT(2010)425621_EN.pdf

Charter of Fundamental Rights of the European Union, 2012/C 326/02 - [2012] OJ C 326/391. https://eur-lex.europa.eu/legal-content/EN/TXT/?uri=celex\%3A12012P\%2FTXT

Choudhry, S. (2014). Article 7 - Respect for private and family life (family life aspects). In S. Peers et al. (Eds.), The EU Charter of Fundamental Rights: A commentary (pp. 183-222). Oxford: Hart Publishing Ltd. Chapter DOI: http://dx.doi.org/10.5040/9781849468350.ch008

Commission Decision of 26 July 2000 pursuant to Directive 95/46/EC of the European Parliament and of the Council on the adequacy of the protection provided by the safe harbour privacy principles and related frequently asked questions issued by the US Department of Commerce (notified under document number C(2000) 2441) - [2000] OJ L 215/7. https://eur-lex.europa.eu/legal-content/EN/ALL/?uri=CELEX\%3A32000D0520

Consolidated versions of the Treaty on European Union and the Treaty on the Functioning of the European Union (TFEU) - [2012] OJ L. 326/47.

https://eur-lex.europa.eu/legal-content/EN/TXT/?uri=celex\%3A12012E\%2FTXT

Const. Court, judgment 21 October 2015, no. 221.

https://www.questionegiustizia.it/data/doc/878/corte_costituzionale-sentenza221_2015.pdf

Council Directive 2000/78/EC of 27 November 2000 establishing a general framework for equal treatment in employment and occupation - [2000] OJ L 303/16. https://eur-lex.europa.eu/legal-content/EN/TXT/?uri=celex\%3A32000L0078

Di Giandomenico, A. (2016). Minors and doping. International Sports Law Review Pandektis, 11(3-4), 294-306. http://predprin.psu.ru/images/citat/aristov/2-2.pdf

Directive 95/46/EC of the European Parliament and of the Council of 24 October 1995 on the protection of individuals with regard to the processing of personal data and on the free movement of such data - [1995] OJ L 281/31.

https://eur-lex.europa.eu/legal-content/en/TXT/?uri=CELEX\%3A31995L0046

Directive 2002/58/EC of the European Parliament and of the Council of 12 July 2002 concerning the processing of personal data and the protection of privacy in the electronic communications sector - [2002] OJ L 201/37. https://eur-lex.europa.eu/legal-content/EN/ALL/?uri=CELEX\%3A32002L0058

Directive 2002/73/EC of the European Parliament and of the Council of 23 September 2002 amending Council Directive 76/207/EEC on the implementation of the principle of equal treatment for men and women as regards access to employment, vocational training and promotion, and working conditions - [2002] OJ L 269/15. https://eur-lex.europa.eu/legal-content/EN/TXT/?uri=CELEX\%3A32002L0073

Directive 2006/54/EC of the European Parliament and of the Council of 5 July 2006 on the implementation of the principle of equal opportunities and equal treatment of men and 
women in matters of employment and occupation - [2006] OJ L 204/23. https://eur-lex.europa.eu/legal-content/EN/TXT/?uri=CELEX\%3A32006L0054

EU Regulation 2016/679 of the European Parliament and of the Council of 27 April 2016 on the protection of natural persons with regard to the processing of personal data and on the free movement of such data, and repealing Directive 95/46/EC (General Data Protection Regulation) [2016] OJL 119/1. https://eur-lex.europa.eu/eli/reg/2016/679/oj

Fausto-Sterling, A. (2000). The five sexes, revisited. The Sciences, 40(4), 38-41. https://doi.org/10.1002/j.2326-1951.2000.tb03504.x

Ferguson-Smith, M. A., \& Ferris, E. A. E. (1991). Gender verification in sport: The need for change? British Journal of Sports Medicine, 25(1), 17-20. http://dx.doi.org/10.1136/bjsm.25.1.17

Finocchiaro, G. (2017). Introduzione al Regolamento europeo sulla protezione dei dati [Introduction to the European Regulation on Data Protection]. Nuove Leggi Civili Commentate, XL(1), 1-18.

Foster, K. (2012). Is there a global sports law? The Entertainment and Sports Law Journal, 2(1): 1. http://doi.org/10.16997/eslj.146

Gooren, J. (2008). Olympic sports and transsexuals. Asian Journal of Andrology, 10(3), 427432. https://doi.org/10.1111/j.1745-7262.2008.00378.x

Healy, M. L., Gibney, J., Pentecost, C., Wheeler, M. J., \& Sonksen, P. H. (2014). Endocrine profiles in 693 athletes in the post competition setting. Clinical Endocrinology, 81(2), 294305. https://doi.org/10.1111/cen.12445

Heggie, V. (2017). Subjective sex: Science, medicine and sex tests in sports. In E. Anderson \& A. Travers (Eds.), Transgender athletes in competitive sport (pp. 131-142). London: Routledge.

Hester, J. D. (2004). Intersex(es) and informed consent: How physicians' rhetoric constrains choice. Theoretical Medicine and Bioethics, 25(1), 21-49. https://doi.org/10.1023/B:META.0000025069.46031.0e

Hughes, I. A. (2008). Disorders of sex development: A new definition and classification. Best Practice \& Research Clinical Endocrinology \& Metabolism, 22(1), 119-134. https://doi.org/10.1016/j.beem.2007.11.001

Ingram, B. J., \& Thomas, C. L. (2019). Transgender policy in sport, a review of current policy and commentary of the challenges of policy creation. Current Sports Medicine Reports, 18(6), 239-247. https://doi.org/10.1249/jsr.0000000000000605

IOC. (2015). IOC consensus meeting on sex reassignment and hyperandrogenism. https://stillmed.olympic.org/Documents/Commissions_PDFfiles/Medical_commission/201 5-11_ioc_consensus_meeting_on_sex_reassignment_and_hyperandrogenism-en.pdf

IOC. (2004). Statement of the Stockholm Consensus on Sex Reassignment in Sports. https://stillmed.olympic.org/Documents/Reports/EN/en_report_905.pdf

Jordan-Young, R., Sönksen, P. H., \& Karkazis, K. (2014). Sex, health and athletes. British Medical Journal, 348(April), 20-22. https://doi.org/10.1136/bmj.g2926

Karkazis, K., Jordan-Yung, R. Davis, G., \& Camporesi, S. (2012). Out of bounds? A critique of the new policies on hyperandrogenism in elite female athletes. The American Journal of Bioethics, 12(7), 3-16. https://doi.org/10.1080/15265161.2012.680533

Kraneborg, H. (2014). Article 8 - Protection of personal data. In S. Peers et al. (Eds.), The EU Charter of Fundamental Rights: A commentary (pp. 223-266). Oxford: Hart Publishing Ltd. Chapter DOI: http://dx.doi.org/10.5040/9781849468350.ch-009

Law 14 April 1982, no. 164, Rules on rectification of attribution of sex. http://www.onig.it/node/10

Lips, H. M. (2020). Sex \& gender. An introduction ( $7^{\text {th }}$ ed.). Long Grove, IL: Waveland.

Lynskey, O. (2014). Deconstructing data protection: The 'added value' of a right to data 
protection in the EU legal order. International and Comparative Law Quarterly, 63, 569597. https://doi.org/10.1017/S0020589314000244

Müller, M. (2016). Constructing gender incommensurability in competitive sport: Sex/Gender testing and the new regulations on female hyperandrogenism. Human Studies, 39, 405-431. https://doi.org/10.1007/s10746-016-9397-1

Ronnestad, B. R., Nygaard, H., \& Raastad. T. (2011). Physiological elevation of endogenous hormones results in superior strength training adaptation. European Journal of Applied Physiology and Occupational Physiology, 111(9), 2249-2259. https://doi.org/10.1007/s00421-011-1860-0

Simpson, J. L., Ljungqvist, A., de la Chapelle, A., Ferguson-Smith, M.A., Genel, M., Carlson, A. S., Ehrhardt, E., \& Ferris, E. (1993). Gender verification in competitive sports. Sports Medicine, 16(5), 305-315. https://doi.org/10.2165/00007256-199316050-00002

Storer, T. W., Magliano, L., Woodhouse, L., Lee, M. L., Dzekov, C., Casaburi, R., \& Bhasin, S. (2003). Testosterone dose-dependently increases maximal voluntary strength and leg power but does not affect fatigability or specific tension. Journal of Clinical Endocrinology and Metabolism, 88(4), 1478-1485. https://doi.org/10.1210/jc.2002-021231

Sudai, M. (2017). The testosterone rule-constructing fairness in professional sport. Journal of Law and the Biosciences, 4(1), 181-193. https://doi.org/10.1093/jlb/lsx004

Sullivan, C. F. (2011). Gender verification and gender policies in elite sport: Eligibility and "fair play". Journal of Sport and Social Issues, 35(4), 400-419. https://doi.org/10.1177/0193723511426293

Sykes, H. (2006). Transsexual and transgender policies in sport. Women in Sport \& Physical Activity Journal, 15(1), 3-13. https://doi.org/10.1123/wspaj.15.1.3

Thiene, A. (2017). Segretezza e riappropriazione di informazioni di carattere personale: Riserbo e oblio nel nuovo Regolamento europeo [Secrecy and reappropriation of personal information: Confidentiality and oblivion in the new European Regulation]. Nuove Leggi Civili Commentate, XL (2), 410-444.

Trans Rights Europe Map \& Index. (2018). https://tgeu.org/trans-rights-map-2018/

Tucker, R., Collins, M. (2009). The science and management of sex verification in sport. South African Journal of Sports Medicine, 21(4), 147-150. https://doi.org/10.17159/2078-516X/2009/v21i4a283

van den Brink, M., \& Dunne, P. (2018). Trans and intersex equality rights in Europe - A comparative analysis. Luxembourg: Publication Office of the European Union.

Vested-Hansen, J. (2014). Article 7 - Respect for private and family life (private life, home, and communication). In S. Peers et al. (Eds.), The EU Charter of Fundamental Rights: A commentary (pp. 153-182). Oxford: Hart Publishing Ltd. Chapter DOI: http://dx.doi.org/10.5040/9781849468350.ch-007

Warren, S. D., \& Brandeis, L. D. (1890). The right to privacy. Harvard Law Review, 4(5), 193220. 